\title{
Phenolic carbon cloth-based electric double-layer capacitors with conductive interlayers and graphene coating
}

\author{
Chunhong Lei ${ }^{1,2} \cdot$ Foivos Markoulidis $^{1} \cdot$ Peter Wilson $^{1} \cdot$ Constantina Lekakou $^{1}$
}

Received: 6 August 2015/Accepted: 8 December 2015/Published online: 28 December 2015

(c) The Author(s) 2015. This article is published with open access at Springerlink.com

\begin{abstract}
Phenolic resin-derived activated carbon (AC) cloths are used as electrodes for large-scale electric doublelayer capacitors or supercapacitors. To increase the energy and power density of the supercapacitor, the contact resistance between the carbon cloth and the aluminium foil current collector is reduced by modifying the $\mathrm{Al}$ current collectors. Different modified Al current collectors, including Toyal-Carbo ${ }^{\circledR}$ (surface-modified $\mathrm{Al}$ ), $\mathrm{DAG}^{\circledR}$ (deflocculated Acheson ${ }^{\mathrm{TM}}$ graphite) coating and
\end{abstract}

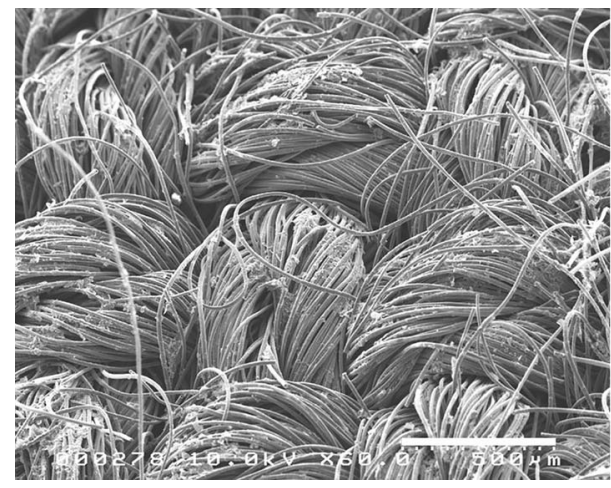

Chunhong Lei

c.lei@soton.ac.uk

Constantina Lekakou

c.lekakou@surrey.ac.uk

1 Advanced Materials Group, Department of Mechanical Engineering Sciences, Faculty of Engineering and Physical Sciences, University of Surrey, Guildford GU2 7XH, UK

2 School of Chemistry, University of Southampton, Southampton SO17 1BJ, UK poly(3,4-ethylenedioxythiophene) (PEDOT) coating, have been tested and compared. The use of modified $\mathrm{Al}$ current collectors are shown to greatly reduce the contact resistance between the $\mathrm{AC}$ cloth and the $\mathrm{Al}$ foil. Another solution investigated in this study is to coat AC cloth with graphene through electrophoretic deposition (EPD). The graphene coated AC cloth is shown increased the capacitance and greatly reduced internal resistance.

\section{Graphical Abstract}

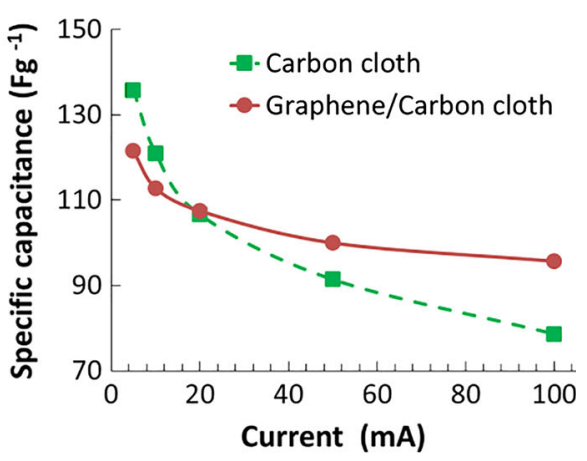

Keywords Phenolic carbon cloth - Conductive interlayer - Graphene coating · Current collector

\section{Introduction}

Electrochemical double-layer capacitors (EDLCs) [1], also known as supercapacitors or ultracapacitors, are fast energy storage and delivery devices, with power and energy density performance in between traditional dielectric capacitors which have high power output, and batteries/fuel cells 
which have large energy storage. They can be used as alternative or complementary power sources in various applications including telecommunication devices, standby power systems, portable electronic devices and hybrid electric vehicles [2].

Phenolic resins have been shown to be very flexible precursors to high-purity carbons, allowing the production of carbon materials with a wide range of pore structures [3, 4]. Phenolic resin-derived AC fibres have been reported as a promising electrode material for high-performance electrochemical supercapacitors [5, 6], due to its high specific area with micro and meso-pores interconnected throughout the whole carbon bulk [7], which ensure free access of charged ions to all the surfaces. Corresponding AC cloths, made of the knitted carbon fibres, can be used directly as electrodes for large area EDLCs. In AC cloths, individual carbon fibres are connected together through weaving or knitting, no binder is involved which can reduce the BET of coating-type electrodes [8]. Furthermore, AC cloth is flexible and tough, AC cloth based EDLCs can be assembled to any shape, such as the curved surface of a car, and is easy to be scaled-up. The disadvantages of AC cloth include high contact resistance with aluminium foil, a commonly used current collector for supercapacitors, and too much free space between the carbon fibres which can waste electrolyte. Woven carbon fibre cloths for example can be compressed to a maximum fibre volume fraction of $65 \%[9,10]$ resulting in $35 \%$ space between carbon fibres.

The high carbon cloth/Al foil contact resistance comes from a low contact area, a lack of adhesion between the carbon material and the aluminium surface, and the intrinsic aluminium oxidation layer formed on the surface of the $\mathrm{Al}$ foil. In order to reduce the carbon/Al contact resistance, a certain modification to the $\mathrm{Al}$ current collector is necessary, either through chemical change of $\mathrm{Al}$ surface, or introducing a conductive interlayer between the carbon cloth and the Al foil which binds the two components together. In this study, a modified Al foil, Toyal-Carbo ${ }^{\circledR}$, with carbon black coated on the surface, was used for current collector, following our previous study [11]. Secondly, a conducting polymer, poly(3,4ethylenedioxythiophene):polystyrene sulphonate (PEDOT:PSS), was used as a interlayer in this study. PEDOT exhibits not only a high conductivity but also an unusual stability in the oxidized state, being considered as the most stable conducting polymer currently available [12]. Therefore, several researchers have considered PEDOT as an electrode material for supercapacitors [13-15], and as a conductive binder for $\mathrm{AC}$ electrodes in our previous study [16]. The advantage of aqueous PEDOT:PSS is that, after drying, the PEDOT:PSS film is highly conducting, mechanically durable and insoluble in common solvents.
Thirdly, a $\mathrm{DAG}^{\circledR}$ (deflocculated Acheson ${ }^{\mathrm{TM}}$ graphite) foil was also used as current collectors in this study. DAG foil is comprised of a dispersion of high-purity micro-graphite particles in thermoplastic material coated onto $\mathrm{Al}$ foil. At elevated temperature, the DAG coating layer is highly adhesive, which can bind the $\mathrm{AC}$ cloth firmly onto $\mathrm{Al}$ foil.

Finally, graphene material was introduced into the carbon cloth in order to reduce its contact resistance with Al. Graphene has been utilized as an alternative electrode material for supercapacitors [17-19] with very good performance, due to its unique properties: large electrical conductivity and/or vast surface area. The introduction of graphene into AC cloth might not only increase its capacitance, but also reduce the $\mathrm{AC}$ cloth/Al contact resistance with graphene as conducting interlayer. In this study, pristine graphene was combined with $\mathrm{AC}$ cloth through electrophoretic deposition (EPD). As the $\mathrm{AC}$ cloth is spongy, there is sufficient space to accommodate these nano materials to form a binary composite textile.

The present study includes an investigation into manufacturing and/or using these interlayers between AC cloth and $\mathrm{Al}$ electrode current collector in the fabrication of full EDLC cells. An organic electrolyte of $1 \mathrm{M}$ tetraethyl ammonium tetrafluoroborate $\left(\mathrm{TEABF}_{4}\right)$ in propylene carbonate (PC) was used, the EDLC cells were analysed using electrochemical impedance spectroscopy (EIS) and galvanostatic charge-discharge (GCD).

\section{Experimental details}

\subsection{Fabrication of capacitors and characterization methods}

For demonstration, full EDLC cells were fabricated in a symmetric configuration. A cellulose-based paper was used as separator, two square pieces of $4 \mathrm{~cm}^{2}$ phenolicderived AC cloth (Kynol 507-15, specified $\mathrm{BET}=1500 \mathrm{~m}^{2} \quad \mathrm{~g}^{-1}$, measured areal density $=12-14 \mathrm{mg} / \mathrm{cm}^{2}, 1-\mathrm{mm}$ thick) as the active electrodes, and outside two pieces of aluminium foils, bare or modified, as the current collectors in contact with the carbon cloth. The electrolyte was $1 \mathrm{M} \mathrm{TEABF}_{4} / \mathrm{PC}$. The EDLCs were tested using EIS and GCD.

The EIS measurements on the EDLC cells were carried out at a DC bias of $0.2 \mathrm{~V}$ with a sinusoidal signal of $20 \mathrm{mV}$ over a frequency range from $1 \mathrm{MHz}$ to $0.01 \mathrm{~Hz}$. From the EIS measurement, a Nyquist plot is obtained and analysed.

GCD tests were carried out on the cells in the potential range of $0-3 \mathrm{~V}$ at current from $50-500 \mathrm{~mA}$. 


\subsection{AC cloth/Toyal-Carbo electrode}

A carbon-modified Al foil, Toyal-Carbo ${ }^{\circledR}$, was used. On the surface of the foil is a thin carbon black-coated layer held by $\mathrm{Al}_{4} \mathrm{C}_{3}$ nano whiskers [11]. The $\mathrm{Al}_{4} \mathrm{C}_{3}$ nanometer scale whiskers were grown from underneath the $\mathrm{Al}$ oxide layer, and hence, they can not only provide electric conducting channels across the oxide layer, but also serve as mechanical lockers to hold carbon particles to the $\mathrm{Al}$ surface. The AC cloth was placed on the modified Al foil directly without any binder, to be used as EDLC electrodes.

\subsection{AC cloth/DAG-Al electrode}

A DAG-coated $(5 \mu \mathrm{m}) \mathrm{Al}$ foil was used as a current collector. The AC cloth was bonded to it by pressing them together with a weight of $50 \mathrm{~g} / \mathrm{cm}^{2}$ while heating the block to $250{ }^{\circ} \mathrm{C}$ for $30 \mathrm{~min}$; after cooling naturally, the carbon cloth adheres to the substrate fairly well.

\subsection{AC cloth/PEDOT-Al electrode}

To prepare PEDOT interlayer, 5wt \% carbon black (acetylene based, Alfa Aesar) was added into PEDOT:PSS (Sigma-Aldrich, $1.3 \mathrm{wt} \%$ dispersion in $\mathrm{H}_{2} \mathrm{O}$ ) solution to make a slurry. The slurry was coated onto the $\mathrm{Al}$ foil using a bar coater with a $30-\mu \mathrm{m}$ gap, which yielded a coating thickness of $\sim 10 \mu \mathrm{m}$ after dried. Immediately after the coating, the AC cloth was placed on top of it and compressed with the aid of a flat steel plate. The block was then dried in an oven at $150{ }^{\circ} \mathrm{C}$ for $2 \mathrm{~h}$; after cooling, the carbon cloth adheres to the substrate fairly well.

\subsection{EPD of graphene on activated carbon cloth}

Unfunctionalized graphene was produced by liquid-phase exfoliation of graphite following the procedure reported by Y. Hernandez [20]: graphite foil (Alfa Aesar, 1-mm thick, $97 \%$ metals basis) was cut into pieces, immersed in NMP (N-methyl-2-pyrrolidone) and exfoliated by sonication for 1 $\mathrm{h}$ in a high-power sonicator. The produced graphene was well dispersed in NMP as is shown in the photograph in Fig. 1a. The graphene dispersions produced this way have concentrations up to approx. $0.01 \mathrm{mg} \mathrm{ml}^{-1}$, with a monolayer yield of approx. $1 \mathrm{wt} \%$, and an absence of defects or oxides. NMP was chosen because its Hansen solubility parameters $(\mathrm{HSP})\left(\delta_{\mathrm{D}}, \delta_{\mathrm{P}}, \delta_{\mathrm{H}}\right)_{\mathrm{NMP}}=(18.3,12.3,7.2)$ $\mathrm{MPa}^{1 / 2}$ [21] are close to those of graphene $\left(\delta_{\mathrm{D}}, \delta_{\mathrm{P}}, \delta_{\mathrm{H}}\right)_{\text {graphene }}=(18,9.3,7.7) \mathrm{MPa}^{1 / 2}[22]$.

The so-produced graphene was then used in the fabrication of a binary composite textile with the AC cloth by EPD (Fig. 1b). Unfunctionalized graphene sheets in NMP are negatively charged; under electric field, the graphene sheets migrate towards the positive electrode and adhere onto the electrode surface via Vander Waals forces. The adhesion can be further reinforced through PVDF (polyvinylidene fluoride) by immersing the graphenecoated AC cloth into a solution of NMP $+5 \mathrm{wt} \%$ PVDF for one minute.
Fig. 1 a Graphene dispersed in NMP. b Diagram of graphene deposition on AC cloth via EPD
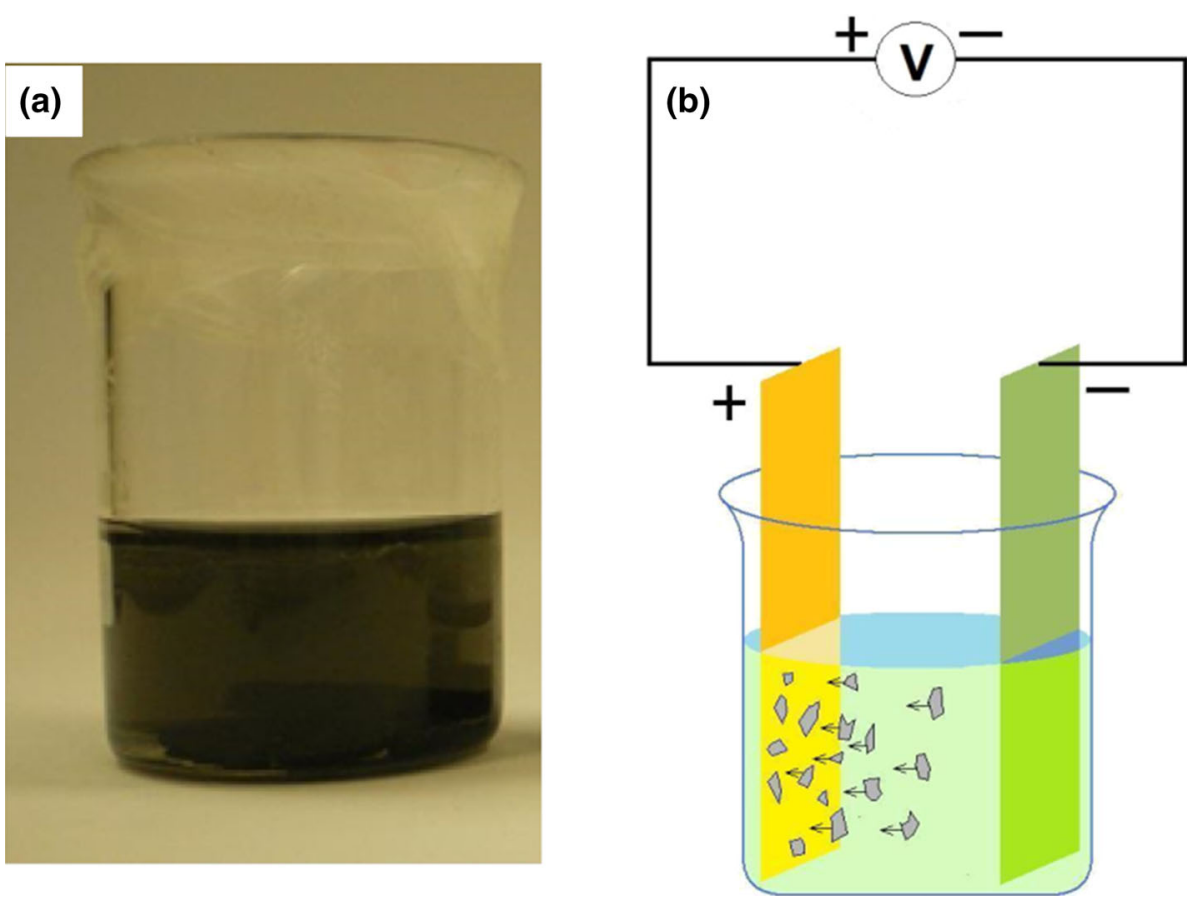


\section{Results and discussion}

\subsection{Effect of modified Al current collectors}

Figure 2 displays the Nyquist plots of the EDLC cells made from $\mathrm{AC}$ cloth/Al electrodes with or without interlayer between the carbon cloth and the Al foil. From the Nyquist plot, the solution resistance $R_{s}$ can be obtained from the left intersection point of the semicircle with the real axis; the diameter of the semicircle represents the charge transfer resistance $R_{c t}$. $R_{s}$ comes from the bulk solution resistance and its magnitude depends on the electrolyte conductivity, the material and thickness of the separator. $R_{c t}$ is the charge transfer resistance, which can be separated into two components: the electronic and the ionic resistances. The electronic resistance includes the intrinsic electronic conductivity of the carbon material fibres, the electronic contact between carbon fibres and the contact between the active layer and the current collector. The ionic resistance is the electrolyte ionic resistance inside the pores of the electrode. It depends on the electrolyte conductivity, porous texture of the electrode and the thickness of active layer. From the Nyquist plot, the total internal resistance of the cell, $R_{i n t}$, can be estimated by

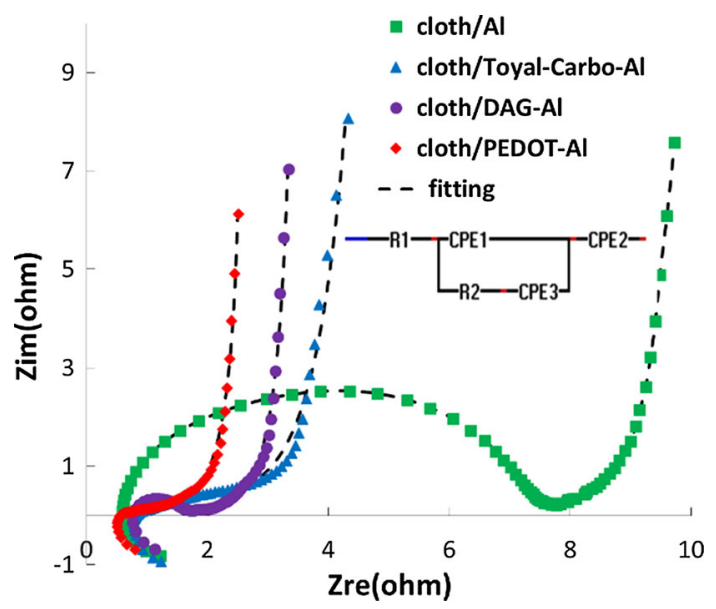

Fig. 2 Nyquist plots (dotted lines) of AC cloth-based EDLCs with different current collectors, and the best fitting (dashed lines) according to the equivalent circuit in the inset extrapolating the low frequency and straight curve on the Nyquist plot to intersect the X-axis [23, 24].

To better understand the EIS measurement, a generalised equivalent circuit model is used to fit the Nyquist plots. The equivalent circuit consists of a bulk solution resistance of the electrolyte $R_{s}$, a charge transfer resistance $R_{c t}$, an interfacial contact capacitance $C_{c}$, an electrical double-layer capacitance $C_{d l}$ and Warburg impedance $Z_{w}$, as presented in Fig. 3a. The fitting of the equivalent circuit model is carried out using the EIS Spectrum Analyser ${ }^{\circledR}$ software according to the equivalent circuit in Fig. 3b, where $R 1$ and $R 2$ represent $R_{s}$ and $R_{c t}$, respectively, and three constant phase elements (CPE), CPE1, CPE2 and CPE3 corresponding to $C_{c}, C_{d l}$ and $Z_{w}$, respectively, as it was found that these Nyquist plots can be fitted better by replacing two pure capacitors and the Warburg elements with three constant phase elements. A CPE has two parameters: $Q$ and $n$, and impedance of this element is given by the formula:

$Z_{C P E}(\omega)=\frac{1}{Q(j \omega)^{n}}$,

where $j$ is imaginary unit and $\omega$ is angular frequency. For $\mathrm{n}=1$, the CPE is a capacitor with capacitance $Q$. For $\mathrm{n}=0$, the CPE is a resistor with resistance $1 / Q$. The units of $Q$ are $S \cdot s^{n}$ ( $S=$ siemens, $s=$ second). Table 1 presents the values of the parameters of the generalized equivalent circuit model for each type of tested supercapacitor cells, which give the best fit of the data of the corresponding Nyquist plots, as shown in Fig. 2 in dashed lines. The fitting is very well, indicating that the equivalent circuit in Fig. $3 \mathrm{~b}$ can represent the actual supercapacitor cells.

As all the cells were constructed in the same way except in the carbon cloth/Al contact, so that the difference of charge transfer resistance $R_{c t}$ between these cells comes from the carbon/Al contact resistance. As can be seen in Table 1, the AC cloth on bare Al foil has the highest contact resistance, $R_{c t}=6.83 \Omega$, the DAG interlayer reduced the contact resistance considerably to $R_{c t}=0.70 \Omega$, as the DAG has worked as a conducting adhesive to bind the individual carbon fibres onto the Al surface; the contact resistance with Toyal-Carbo and PEDOT interlayers is less than $0.05 \Omega$, as the carbon cloth contact with Toyal-Carbo is merely carbon-carbon contact, and the PEDOT has also

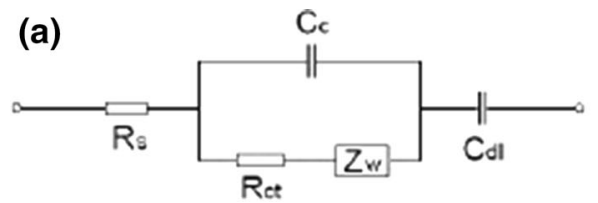

(b)

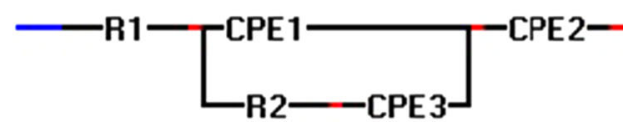

Fig. 3 a Generalised equivalent circuit model used for all supercapacitor cells; b corresponding equivalent circuit model used in EIS spectrum analyser for the fitting 
Table 1 Parameters of the generalised equivalent circuit model for each type of cells derived from the best numerical fitting of the EIS experimental data

\begin{tabular}{|c|c|c|c|c|c|c|c|c|}
\hline \multirow{2}{*}{$\begin{array}{l}\text { Cell with electrodes } \\
\text { Cloth/Al }\end{array}$} & \multirow{2}{*}{$\begin{array}{l}\mathrm{R} 1(\Omega) \\
0.57\end{array}$} & \multirow{2}{*}{$\begin{array}{l}\mathrm{R} 2(\Omega) \\
6.83\end{array}$} & \multicolumn{2}{|l|}{$\begin{array}{l}\text { CPE1 } \\
\text { Q1 }\left(\mathrm{S} \cdot \mathrm{s}^{n}\right) n\end{array}$} & \multicolumn{2}{|c|}{$\begin{array}{l}\text { CPE2 } \\
\text { Q2 }\left(\mathrm{S} \cdot \mathrm{s}^{n}\right) n\end{array}$} & \multicolumn{2}{|c|}{$\begin{array}{l}\text { CPE3 } \\
\text { Q3 }\left(\mathrm{S} \cdot \mathrm{s}^{n}\right) n\end{array}$} \\
\hline & & & $2.96 \times 10^{-5}$ & 0.84 & 2.88 & 1.04 & 0.74 & 0.29 \\
\hline Cloth/Toyal-Carbo-Al & 0.85 & 0.05 & $2.86 \times 10^{-3}$ & 0.74 & 2.32 & 1.01 & 0.44 & 0.17 \\
\hline Cloth/DAG-Al & 0.75 & 0.70 & $6.25 \times 10^{-6}$ & 0.93 & 2.59 & 1.02 & 0.75 & 0.17 \\
\hline Cloth/PEDOT-Al & 0.58 & 0.03 & $5.47 \times 10^{-3}$ & 0.63 & 3.13 & 1.02 & 0.73 & 0.17 \\
\hline
\end{tabular}

worked as a conducting adhesive to bind the individual carbon fibres onto the Al surface. Thus, the modified Al and conducting interlayers have greatly reduced the conducting resistance. This prove that the high carbon fibre cloth/Al foil contact resistance is due to a low contact area and a lack of adhesion between the carbon material and the Al surface, and the intrinsic $\mathrm{Al}$ oxidation layer formed on the surface of the Al foil. The cloth/PEDOT-Al electrode has the lowest internal resistance $R_{\text {int }}$ among all the electrodes, and this might due to the penetration of PEDOT into bulk AC cloth during heating and pressing process in the preparation of the electrode, in addition to the reduced contact resistance by conducting PEDOT. It can also be seen that the cell with the PEDOT binder shows the highest capacitance (biggest $Q$ value in Table 1), which is due to the added pseudocapacitance from PEDOT.

Figure 4 displays GCD curves for each of these cells at a current of $50 \mathrm{~mA}$ and $200 \mathrm{~mA}$. All cells showed approximately linear charge-discharge curves, suggesting that the electrodes tested have no obvious redox reaction.

The $I R$ drop at the turning point of the charge-discharge line is much smaller for cells with modified current collectors due to the reduced $\mathrm{AC}$ cloth/Al contact resistance, which is more obvious at the high current of $200 \mathrm{~mA}$. The capacitances of these EDLC cells are similar, as the AC cloth is the main contributor to total capacitance. A slightly higher capacitance is exhibited in the cell with the PEDOT binder at $50 \mathrm{~mA}$ discharge current, in that its discharge slop $\Delta V / \Delta t$ is smaller. This added capacitance is from the pseudocapacitance of PEDOT, which become smaller at $200 \mathrm{~mA}$ due to the slower charge-discharge process of pseudocapacitance.

\subsection{Graphene-coated AC cloth}

Pristine graphene was deposited on carbon cloth by EPD at $30 \mathrm{~V}$ for $30 \mathrm{~min}$ from a solution of graphene in NMP prepared by sonication of graphite foil. Longer deposition time was found can increase the amount of graphene deposited on carbon cloth. EPD times longer than 30 min resulted in electrodes with increased resistance or an additional resistance from the graphene interlayer. SEM images on Fig. 5 show that graphene sheets with large range of sizes adhered on the carbon fabrics everywhere. The graphene sheets will not be adhered to the cloth if the cloth was merely dipped into the graphene dispersion without applying a voltage to it. The adhesion of graphene on carbon cloth is through Vander Waals forces which are very weak. To prevent graphene removal by the electrolyte, PVDF was added. The consequence is that PVDF polymer may cover some micro-pores on the carbon fibres, as can be seen in magnified SEM image in Fig. 5d. The electrochemical performance of graphene-coated AC cloth was analysed using Toyal-Carbo current collector. The ToyalCarbo led to much lower contact resistance than bare $\mathrm{Al}$; the cloth/Toyal-carbo-Al electrode is easy to prepare: it does not require any heat-pressing process to integrate the interlayer, which made this system easier to be used in the fabrication of large pouch cells. The low contact resistance results from direct carbon-carbon contact between the carbon cloth and the beads-like carbon black on the surface of Toyal-Carbo foil (Fig. 5e).

Shown in Fig. 6a is the Nyquist plot of EDLC cells with bare AC cloth and graphene-coated AC cloth electrodes. In both cells, the charge transfer resistance $R_{c t}$ is the same,
Fig. 4 GCD curves of AC cloth-based EDLCs with different current collectors at a current of $50 \mathrm{~mA}$ (a) and $200 \mathrm{~mA}(\mathbf{b})$
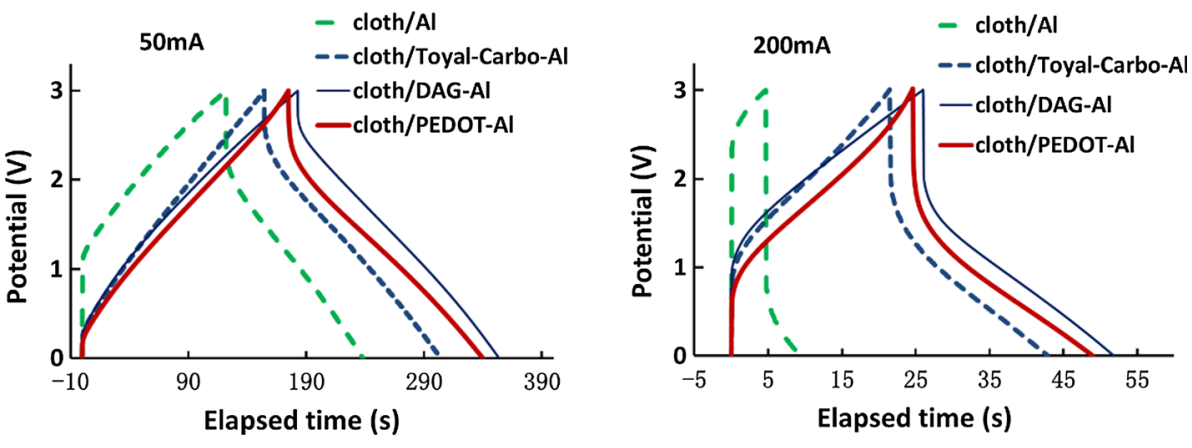

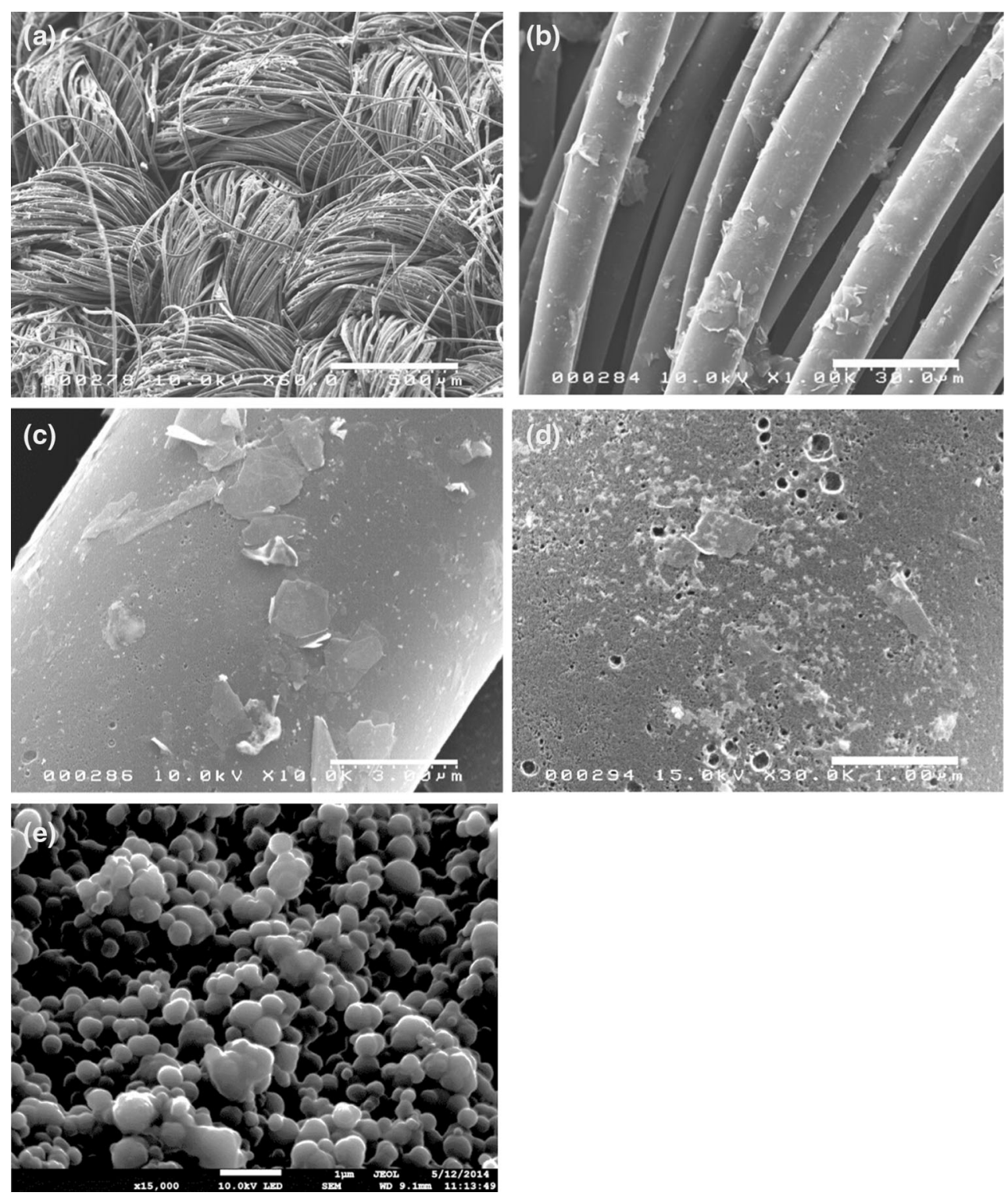

Fig. 5 SEM images of graphene-coated AC cloth by EPD (a-d), and the surface of Toyal-Carbo current collector (e)

indicating that graphene does not change the contact resistance. However, the cell with graphene-coated AC cloth shows lower internal resistance $R_{i n t}$ and higher capacitance. The reduction of internal resistance in graphene-coated AC cloth is due to the filling and bridging of graphene sheets between the carbon fibres, and between the carbon fibres and Al surface. Graphene increases the overall capacitance by providing additional surface area to the AC electrode without increase of the total weight, as the graphene is so light that the deposition of graphene on the cloth has hardly changed its weight. The GCD curves of the two cells at $50 \mathrm{~mA}$ in Fig. 6b also indicate the higher capacitance and lower internal resistance with graphene-coated carbon cloth.

Electrode mass-specific capacitance was calculated from the discharge slopes of the charge-discharge cycles at different currents, and is plotted against current as shown in Fig. 7. It can be seen from this figure that the capacitance of the graphene-coated $\mathrm{AC}$ cloth at the low power end is lower than the AC cloth without graphene coating. This is maybe due to blocking of part of the micro-pores on the carbon fibres, these micro-pores contribute to the overall capacitance mainly in the lower power region. However, the capacitance of the AC cloth drops rapidly with increasing current, while the decrease of the capacitance with increasing current is slower at the beginning for graphene-coated AC cloth, which soon caught up with and surpassed AC cloth when the current increased above $20 \mathrm{~mA}$, and kept relatively constant over a large rang of current. This is translated to higher energy density at high currents for the graphene-coated AC cloth, in other words, the rate performance is improved. 
Fig. 6 Two EDLCs with bare and graphene-coated $\mathrm{AC}$ cloth electrodes on Toyal-Carbo: a Nyquist plots; $\mathbf{b}$ GCD curves

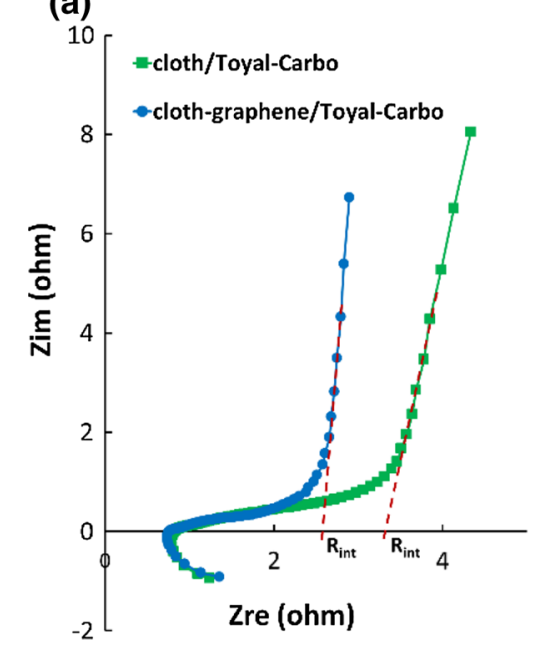

(b)

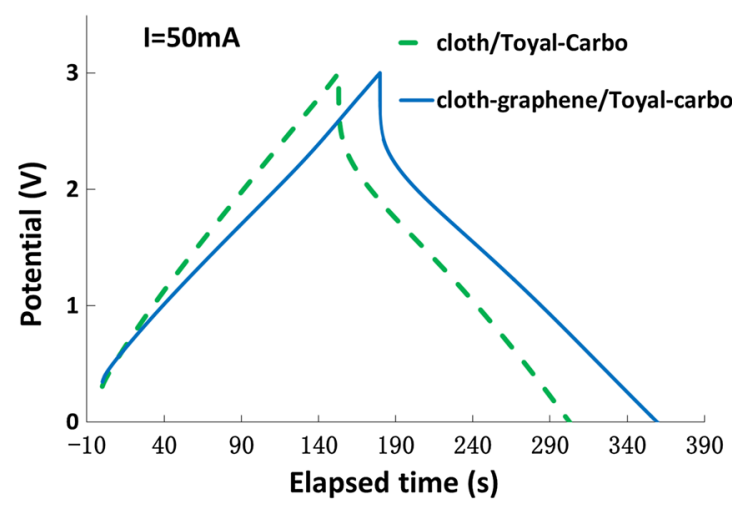

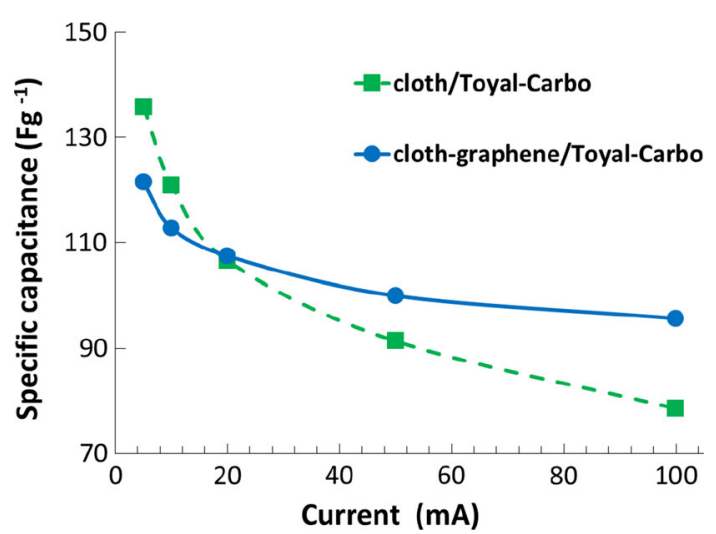

Fig. 7 Ragone plots of bare and graphene-coated AC cloth electrodes on Toyal-Carbo

\section{Conclusions}

Phenolic resin-derived AC cloth-based EDLCs were developed with consistently high performance by applying different modified $\mathrm{Al}$ foil current collectors, which greatly reduced the contact resistance. PEDOT interlayer increased the overall capacitance with added pseudocapacitance. The EPD coating of graphene onto the AC cloth, although hardly changed its weight, nevertheless has produced obvious change in its performance in EDLC cell, with reduced internal resistance, increased overall capacitance and improved rate performance by reducing the internal resistance.

Acknowledgments This study was funded by the European Community FP7 project AUTOSUPERCAP.

Open Access This article is distributed under the terms of the Creative Commons Attribution 4.0 International License (http://crea tivecommons.org/licenses/by/4.0/), which permits unrestricted use, distribution, and reproduction in any medium, provided you give appropriate credit to the original author(s) and the source, provide a link to the Creative Commons license, and indicate if changes were made.

\section{References}

1. Khomenko V, Raymundo-Pĩnero E, B́eguin F (2008) High-energy density graphite/AC capacitor in organic electrolyte. J Power Sources 177:643-651

2. Burke A (2000) Ultracapacitors: why, how, and where is the technology. J Power Sources 91:37-50

3. Tennison SR (1998) Phenolic-resin-derived activated carbons. Appl Catal A 173:289-311

4. Szczurek A, Jurewicz K, Amaral-Labat G, Fierro V, Pizzi A, Celzard A (2010) Structure and electrochemical capacitance of carbon cryogels derived from phenol-formaldehyde resins. Carbon 48:3874-3883

5. Xue R, Yan J, Liu X, Tian Y, Yi B (2011) Effect of activation on the carbon fibers from phenol-formaldehyde resins for electrochemical supercapacitors. J Appl Electrochem 41:1357-1366

6. Nawa M, Nogami T, Mikawa H (1984) Application of activated carbon fiber fabrics to electrodes of rechargeable battery and organic electrolyte capacitor. J Electrochem Soc 131:1457-1459

7. Lei C, Amini N, Markoulidis F, Wilson P, Tennison S, Lekakou C (2013) Activated carbon from phenolic resin with controlled mesoporosity for an electric double-layer capacitor (EDLC). J Mater Chem A 1:6037-6042

8. Markoulidis F, Lei C, Lekakou C, Duff D, Khalil S, Martorana B, Cannavaro I (2014) A method to increase the energy density of supercapacitor cells by the addition of multiwall carbon nanotubes into activated carbon electrodes. Carbon 68:58-66

9. Saunders RA, Lekakou C, Bader MG (1998) Compression and microstructure of fibre plain woven cloths in the processing of polymer composites. Compos A 29A:443-454

10. Saunders RA, Lekakou C, Bader MG (1999) Compression in the processing of polymer composites 1. A mechanical and microstructural study for different glass fabrics and resins. Compos Sci Technol 59:983-993

11. Lei C, Markoulidis F, Ashitaka Z, Lekakou C (2013) Reduction of porous carbon/Al contact resistance for an electric doublelayer capacitor (EDLC). Electrochim Acta 92:183-187

12. Groenendaal BL, Jonas F, Freitag D, Pielartzik H, Reynolds JR (2000) Poly(3,4-ethylenedioxythiophene) and its derivatives: past, present, and future. Adv Mater 12:481-534 
13. Ryu KS, Lee Y-G, Hong Y-S, Park YJ, Wu X, Kim KM, Kang MG, Park N-G, Chang SH (2004) Poly(ethylenedioxythiophene) (PEDOT) as polymer electrode in redox supercapacitor. Electrochim Acta 50:843-847

14. Laforgue A (2011) All-textile flexible supercapacitors using electrospun poly(3,4-ethylenedioxythiophene) nanofibers. J Power Sources 196:559-564

15. Liu R, Cho SI, Lee SB (2008) Poly(3,4-ethylenedioxythiophene) nanotubes as electrode materials for a high-powered supercapacitor. Nanotechnology 19:215710-215718

16. Lei C, Wilson P, Lekakou C (2011) Effect of poly(3,4ethylenedioxythiophene) (PEDOT) in carbon-based composite electrodes for electrochemical supercapacitors. J Power Sources 196:7823-7827

17. Shao Y, El-Kady MF, Wang LJ, Zhang Q, Li Y, Wang H, Mousavi MF, Kaner RB (2015) Graphene-based materials for flexible supercapacitors. Chem Soc Rev 11:3639-3665

18. Vermisoglou EC, Devlin E, Giannakopoulou T, Romanos G, Boukos N, Psycharis V, Lei C, Lekakou C, Petridis D, Trapalis C (2014) Reduced graphene oxide/iron carbide nanocomposites for magnetic and supercapacitor applications. J Alloys Compd 590:102-109

19. Liu C, Yu Z, Neff D, Zhamu A, Jang BZ (2010) Graphene-based supercapacitor with an ultrahigh energy density. Nano Lett 10:4863-4868

20. Hernandez Y et al (2008) High-yield production of graphene by liquid-phase exfoliation of graphite. Nature Nanotech 3:563-568

21. Hansen CM (2007) Hansen solubility parameters: a user handbook, CRC press

22. Hernandez Y, Lotya M, Rickard D, Bergin SD, Coleman JN (2010) Measurement of multicomponent solubility parameters for graphene facilitates solvent discovery. Langmuir 26:3208-3213

23. Stoller MD, Ruoff RS (2010) Best practice methods for determining an electrode material's performance for ultracapacitors. Energy Environ Sci 3:1294-1301

24. Zhao S, Wu F, Yang L, Gao L, Burke AF (2010) A measurement method for determination of dc internal resistance of batteries and supercapacitors. Electrochem Commun 12:242-245 